\title{
Erratum to: Post-orogenic shoshonitic magmas of the Yzerfontein pluton, South Africa: the 'smoking gun' of mantle melting and crustal growth during Cape granite genesis?
}

\author{
J. D. Clemens, I. S. Buick, D. Frei, C. Lana and A. Villaros
}

Erratum to: Contrib Mineral Petrol (2017) 172:72

DOI: $10.1007 / \mathrm{s} 00410-017-1390-9$

The published version of the original paper contained a $\mathrm{Sr}$ isotope analysis of Hornblende-pyroxene quartz monzodiorite sample H25, from the shoshonitic part of the

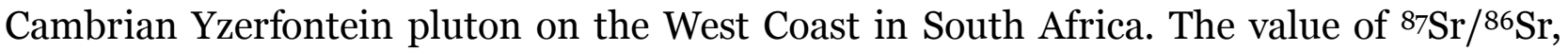
calculated at our newly determined $\mathrm{U}-\mathrm{Pb}$ zircon age of $535 \mathrm{Ma}$, was given as $0.70885 \pm 2$ (20). In the paper, this was reported as an anomalously high value and we hypothesised that this might have been due to the crustal component of this particular magma having been somewhat more radiogenic than for the rest of the shoshonitic samples from the Yzerfontein pluton.

We emphasise that the isotopic and elemental analyses were carried out on the same solutions. Nothing in the $\mathrm{Rb} / \mathrm{Sr}$ ratio in the isotope results suggested analytical problems. However, this result was sufficiently surprising that we provided AEON Labs (UCT) with a second aliquot to dissolve and analyse. The redetermined value of ${ }^{87} \mathrm{Sr} /{ }^{86} \mathrm{Sr}_{535} \mathrm{MA}$ is 0.70506 \pm 2 , which is very similar to all the other determinations for the shoshonitic rocks of the pluton. Although we remain unable to explain the original result, we believe it to have been erroneous and that the correct initial $\mathrm{Sr}$ isotope ratio of sample $\mathrm{H} 25$ is 0.70506 . Accordingly, we present a revised Table 1, showing the $\mathrm{Sr}$ and $\mathrm{Nd}$ isotope data, with the correction, and a revised version of Figs. 6 and 13 in the original paper, as Figs. 1 and 2 here, with the correct value for H25 plotted. This amendment has no impact on the main conclusions of the original paper. 
Table 1 Whole-rock $\mathrm{Rb}-\mathrm{Sr}$ and $\mathrm{Sm}-\mathrm{Nd}$ isotope data for Yzerfontein samples

\begin{tabular}{|c|c|c|c|c|c|c|c|c|c|c|c|c|c|c|}
\hline \multirow{2}{*}{$\frac{\text { Sample no. }}{\mathrm{J} 1}$} & \multirow{2}{*}{$\frac{\text { Rock-type }}{\text { Monzonite }}$} & $\mathrm{Rb}(\mathrm{ppm})$ & $2 \sigma_{\mathrm{m}}$ & \multicolumn{2}{|c|}{$\mathrm{Sr}(\mathrm{ppm})$} & \multirow{2}{*}{$2 \sigma_{\mathrm{m}}$} & ${ }^{87} \mathrm{Rb} /{ }^{86} \mathrm{Sr}$ & \multicolumn{2}{|l|}{${ }^{87} \mathrm{Sr} /{ }^{86} \mathrm{Sr}$} & $2 \sigma_{\mathrm{m}}$ & \multicolumn{3}{|c|}{${ }^{87} \mathrm{Sr} /{ }^{86} \mathrm{Sr}$ at $535 \mathrm{Ma}$} & \multirow{2}{*}{$\frac{2 \sigma}{4}$} \\
\hline & & 178 & & 777 & & & 0.663 & 0.71063 & & 1 & 0.70566 & & 4 & \\
\hline J6 & Monzodiorite & 154 & & 868 & & & 0.513 & 0.70956 & & 2 & 0.70571 & & & 3 \\
\hline $\mathrm{J} 15$ & Monzonite & 166 & & 810 & & & 0.593 & 0.71021 & & 1 & 0.70576 & & & 3 \\
\hline J16 & Monzodiorite & 128 & & 655 & & & 0.566 & 0.70980 & & 2 & 0.70556 & & & 4 \\
\hline J27 & Monzonite & 159 & & 891 & & & 0.516 & 0.70919 & & 2 & 0.70532 & & & 3 \\
\hline $\mathrm{H} 10$ & Monzonite & 183 & 0.6 & 815 & & 3.7 & 0.648 & 0.710567 & & 12 & 0.70570 & & & 4 \\
\hline H11 & Quartz monzonite & 211 & 1.7 & 734 & & 6.5 & 0.831 & 0.712006 & & 10 & 0.70577 & & & 7 \\
\hline H12 & Syenogranite dyke & 213 & 0.4 & 441 & & 1.1 & 1.397 & 0.715740 & & 13 & 0.70526 & & & 8 \\
\hline H13 & Quartz diorite & 53 & 0.2 & 1287 & & 1.5 & 0.120 & 0.705268 & & 14 & 0.70437 & & & 1 \\
\hline $822 \mathrm{~B}$ & Hornblendite cumulate & 16 & 0.3 & 820 & & 19.1 & 0.057 & 0.704730 & & 9 & 0.70430 & & & 1 \\
\hline $\mathrm{H} 24$ & Monzonite enclave & 188 & 1.5 & 948 & & 12.6 & 0.575 & 0.709445 & & 14 & 0.70513 & & & 3 \\
\hline $\mathrm{H} 25$ & Monzodiorite & 88 & 1.0 & 1378 & & 30.8 & 0.185 & 0.706449 & & 11 & 0.70506 & & & 2 \\
\hline H26 & Monzodiorite & 111 & 1.6 & 1458 & & 9.1 & 0.219 & 0.706850 & & 11 & 0.70521 & & & 1 \\
\hline Sample no. & Rock-type & $\mathrm{Sm}(\mathrm{ppm})$ & $2 \sigma_{\mathrm{m}}$ & $\mathrm{Nd}(\mathrm{ppm})$ & $2 \sigma_{\mathrm{m}}$ & ${ }^{147} \mathrm{~S}$ & ${ }^{144} \mathrm{Nd} \quad{ }^{14}$ & ${ }^{143} \mathrm{Nd} /{ }^{144} \mathrm{Nd}$ & $2 \sigma_{\mathrm{m}}$ & & $535 \mathrm{Ma}$ & $2 \sigma$ & $t_{2 \mathrm{DM}} \mathrm{C}$ & \\
\hline $\mathrm{H} 10$ & Monzonite & 13.6 & 0.1 & 69.3 & 0.8 & 0.11 & & 0.512268 & 10 & -1 & & 0.2 & 1.43 & \\
\hline H11 & Quartz monzonite & 12.7 & 0.2 & 66.6 & 0.2 & 0.11 & & 0.512268 & 9 & -1 & & 0.2 & 1.41 & \\
\hline H12 & Syenogranite dyke & 6.73 & 0.10 & 38.8 & 0.4 & 0.10 & & 0.512235 & 11 & -1 & & 0.2 & 1.40 & \\
\hline H13 & Quartz diorite & 4.40 & 0.08 & 24.2 & 0.2 & 0.10 & & 0.512312 & 13 & -0 & & 0.2 & 1.31 & \\
\hline $822 \mathrm{~B}$ & Hornblendite cumulate & 12.43 & 0.06 & 62.3 & 0.2 & 0.12 & & 0.512354 & 9 & -0 & & 0.2 & 1.30 & \\
\hline $\mathrm{H} 24$ & Monzonite enclave & 11.24 & 0.09 & 57.1 & 0.8 & 0.11 & & 0.512292 & 15 & -1 & & 0.2 & 1.39 & \\
\hline $\mathrm{H} 25$ & Monzodiorite & 13.78 & 0.14 & 68.3 & 1.5 & 0.12 & & 0.512301 & 12 & -1 & & 0.2 & 1.39 & \\
\hline $\mathrm{H} 26$ & Monzodiorite & 12.54 & 0.28 & 61.4 & 0.1 & 0.12 & & 0.512320 & 13 & -1 & & 0.2 & 1.37 & \\
\hline
\end{tabular}

Samples J1, J6, J15, J16 and J27 from Jordaan et al. (1995), with $2 \sigma_{\mathrm{m}}$ errors of $0.2 \mathrm{ppm}$ assumed for Rb and Sr concentrations Samples H10, H11, H12, H13 822B, H24, H25 and H26 from present work 

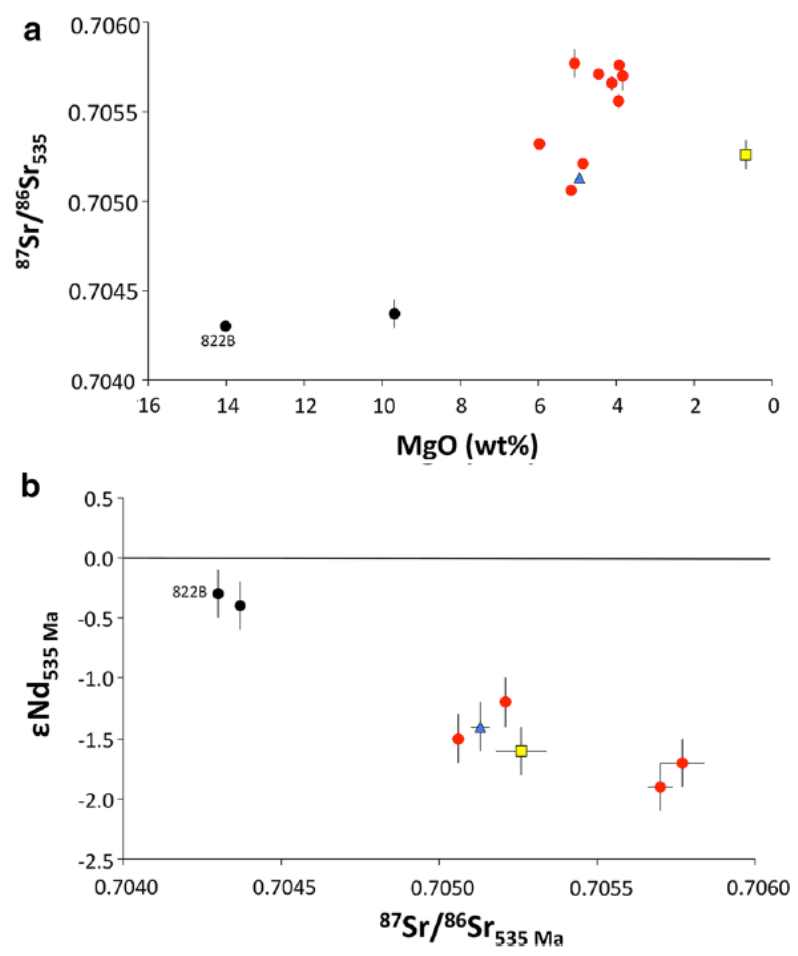

Fig. 1 Diagrams illustrating the $\mathrm{Sr}$ and $\mathrm{Nd}$ isotope variations in the rocks of the Yzerfontein pluton, a initial ${ }^{87} \mathrm{Sr} /{ }^{86} \mathrm{Sr}$ plotted against $\mathrm{MgO}$ (wt\%), b $\varepsilon \mathrm{Nd}_{\text {t }}$ plotted against initial ${ }^{87} \mathrm{Sr} /{ }^{86} \mathrm{Sr}$. The colour coding is as given in Fig. 4, with the hornblendite cumulate rock (822b) labelled. In a, the $2 \sigma$ error bars for initial ${ }^{87} \mathrm{Sr} /{ }^{86} \mathrm{Sr}$ are plotted but are all smaller than the plot symbols. The same is true in $\mathbf{b}$, except for the micromonzogranite sample H12 (yellow square). See the original paper for a discussion of these plots 

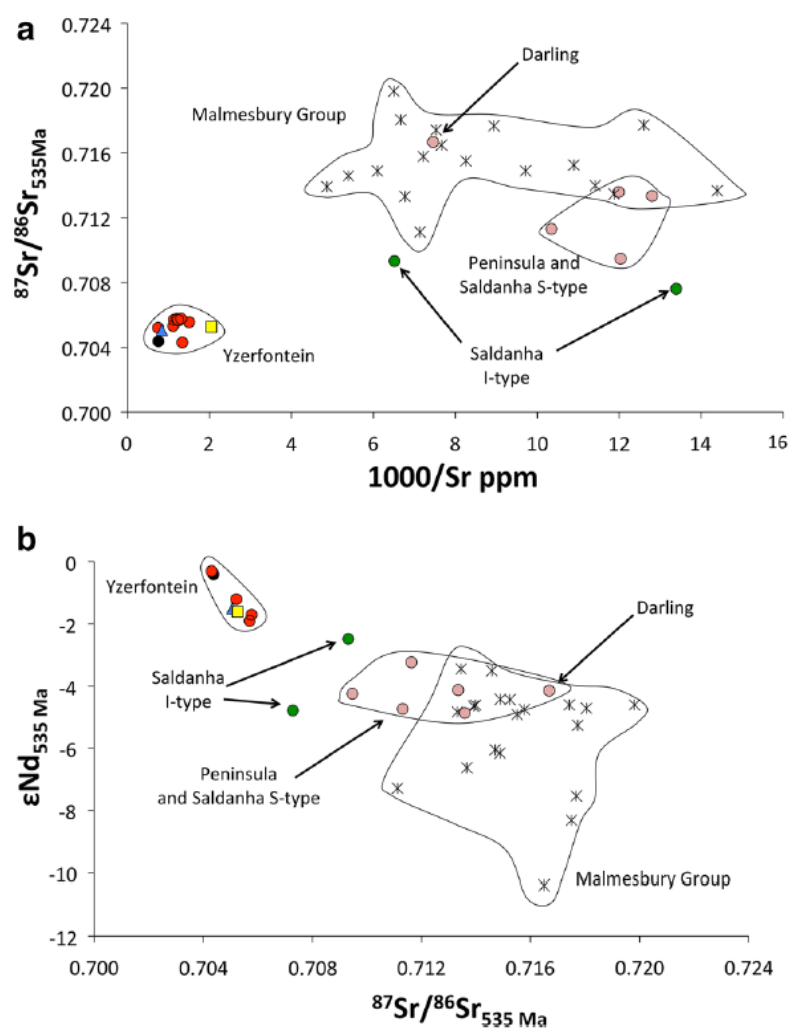

Fig. 2 Isotope plots illustrating the relationships between the rocks of the Yzerfontein pluton, the Cape Granite Suite granitic rocks (CGS) S-type (pink dots) and I-type (dark green dots) and the metasedimentary rocks of the Malmesbury Group (stars), with all isotope ratios normalised to the new $535 \mathrm{Ma}$ age for the Yzerfontein pluton, a Sr isotope mixing plot, with initial ${ }^{87} \mathrm{Sr} /{ }^{86} \mathrm{Sr}$ plotted against $1000 / \mathrm{Sr}$, b isotope correlation diagram, with $\varepsilon \mathrm{Nd}_{t}$ plotted against initial ${ }^{87} \mathrm{Sr} /{ }^{86} \mathrm{Sr}$. See the original paper for data provenance and discussion 